\title{
CRISIS ESPAÑOLA, AFECTACIÓN DE LAS REMESAS EN LA PROVINCIA DE SANTA ELENA, PERIODO 2010 - 2013
}

\section{THE SPANISH CRISIS, AFFECTATION OF THE REMITTANCES IN THE PROVINCE OF SANTA ELENA, 2010-2013}

\author{
Wilson León Valle, MS.c \\ Docente UPSE \\ misiowill@yahoo.es \\ América Meza Bajaña, Mgs, Docente UPSE \\ Sandra Canalías Lamas, MS.c, Docente UPSE \\ Milton González Santos, MS.c, Docente UPSE
}

\section{RESUMEN}

La migración ha sido uno de los temas más acuciantes de la problemática mundial, que lejos de ser contemplado en las agendas gubernamentales, no se le ha dado la importancia debida. Es así que el fenómeno de la migración causa un sinnúmero de efectos que conlleva a que los países entren en una desestabilización en sus políticas públicas, ya que soportan, entre otras cosas, la fuga del capital. Dentro de este contexto, se desarrolla uno de los acontecimientos más recientes, como es la crisis española, la cual afectó, no sólo a países europeos, sino también a países latinoamericanos, entre ellos, el Ecuador. A inicio del siglo XXI, Ecuador entró en crisis económica, política y social, lo que ocasionó que migraran más de 3 millones de ecuatorianos a distintos países, incluido España. De la provincia de Santa Elena, se estima que emigraron aproximadamente más de 3 mil lugareños, lo que causó dependencia a sus familiares, de las remesas provenientes de estos países. La investigación, tiene como propósito determinar el nivel de afectación en las remesas de los migrantes en el presupuesto familiar; uno de los hallazgos más significativos, es que se han incrementado los rubros que recibe la provincia, no sólo de la población que se encuentra en el exterior, también, producto de los migrantes residentes, entre ellos jubilados, lo que constituye un dinamizador de la economía local.

Palabras claves: economía, migración, remesas, familias, crisis social.

\begin{abstract}
Migration has been one of the most pressing issues of world problems, that far from being discussed in governmental agendas, it has not been given its due importance. Thus the phenomenon of migration causes a number of effects that lead countries into a destabilization in their public policies, since, among otherthingsthere is significant outflow of capital. In this context, we develop one of the most recent events, as is the economic crisis in Spain, which affected not only European countries but also Latin American countries, including Ecuador. At the beginning of the 21stcentury, Ecuador entered into an economic, political and social crisis, which caused over 3million Ecuadorians to migrate to different countries, including Spain. In the Santa Elena province, it is estimated that more than 3 thousand individuals migrated, causing a family dependence associated with the remittances from these countries. In this research, one of the most significant findingsis that the areas of increased remittances to the province not only from the population that resides abroad, but also as a product of the immigrant residents, including the incoming retirees, which provide a boost to the local economy.
\end{abstract}

Keywords: economics, migration, remittances, families, social crisis.

Recibido: octubre 2014 Aprobado: febrero 2015

\section{Introducción}

A principios del siglo XXI los países desarrollados han sufrido un impacto en su economía, esto ocurre por diferentes factores, que van desde; lo político, social, cultural, legal, económico, entre otros, que debilitan la riqueza de una nación, tal es el caso de España, que desde el 2008 ha enfrentado una de las crisis económica más impresionante de toda su historia, ante esta situación la pregunta que resulta es: ¿Cuáles fueron los factores que incidieron para que se acreciente la crisis económica en España? 
La importancia de determinar los factores radica en conocer ¿Cómo la crisis económica española repercute en la economía de la Provincia de Santa Elena?

Siendo España uno de los países que registra un elevado índice de migración de los habitantes de la Provincia de Santa Elena, el tema propuesto es de relevancia, ya que, permite conocer el grado de afectación económica y social que sufren las familias que recibían las remesas y que son los directamente perjudicados con la problemática planteada.

Según el Instituto Nacional de Estadísticas y Censos (INEC 2010), son 3000 las familias que dependen de este rubro, constituyéndose, el cantón La Libertad en el centro económico de la provincia, por lo tanto, es el lugar de concentración de las divisas, que luego fueron distribuidas hacia los diferentes sectores y familias de la población, datos obtenidos del Instituto Nacional de Estadística y Censos (1).

La investigación realizada, muestra que al ser la provincia de Santa Elena, eminentemente turísti$\mathrm{ca}$, tiene un flujo de remesas provenientes de las personas que realizan esta actividad. Sin embargo, no refleja la realidad económica y social de los nativos de esta zona. Ya que resultados obtenidos, más allá de demostrar una afectación negativa, refleja un aumento en las remesas en los años objeto de este estudio.

Es importante destacar que las personas que no viven de la actividad turística y que dependen de las remesas de los familiares que viven en el exterior, si han tenido una disminución en sus ingresos por estos rubros, lo que ocasiona inestabilidad económica y social, que se evidencia en los resultados.

Durante el Siglo XXI el importe percibido por la llagada de remesas de España al Ecuador se torno indispensable, ya que se constituyó en uno de los más importantes ingresos percibidos en el país. La disminución de estos ingresos ha afectado notablemente en la economía de las familias que viven en la Provincia de Santa Elena lo repercute en su desarrollo social y económico.

Por otro lado, la investigación es pertinente porque permitió conocer cuál fue el destino de las remesas percibidas, y de cómo este recurso económico sirvió como dinamizador de la economía familiar, local, y de su repercusión en la provincia de Santa Elena.

Del mismo modo, se pretende establecer la incidencia que tuvo en su momento la llegada de remesas de los migrantes, así como evidenciar el detrimento de los presupuestos familiares en aquellos hogares en los que por la crisis española ese dinero no llegó.
Finalmente, es fundamental para la investigación saber cuál fue el nivel y áreas de afectación que sufrió la población en la provincia de Santa Elena por la crisis española, ya que esto, sirvió como insumo para conocer qué tipo de actividades se realizaron durante este periodo, para contrarrestar directamente o colateralmente el daño económico con repercusiones sociales que causo la disminución de las remesas.

\section{Contexto teórico de la situación}

En el Ecuador, las principales fuentes de ingresos para sostener la dolarización que tuvo sus orígenes en la crisis financiera y posterior feriado bancario fueron, en este orden: el petróleo y las remesas enviadas por los migrantes. (2)

Los tiempos de bonanza en España han sufrido los efectos de la crisis internacional que avanza al galope por toda Europa. Es notable interpretar la importancia de estos efectos económicos dentro del contexto de la realidad ecuatoriana, donde dichos resultados, producto del impacto macro económico contribuyeron a la reducción de la crisis en el Ecuador. Sin embargo, esta problemática terminó siendo parte de la realidad económica en el contexto latinoamericano.

Los que dejaron todo, entre ellos profesionales del más alto nivel, para trabajar y ganar dólares en España con el objetivo de enviar dinero a los suyos, se dedicaron a los oficios que pudieron, como por ejemplo: a cuidar ancianos, en actividades de granja; cultivar y cosecha vegetales, entre otras ocupaciones, muchas veces en condiciones no apropiadas para un ser humano, ellos fueron quienes afianzaron las bases económicas, para asegurar la dolarización, ya que el envió de dinero, sostuvo la economía del país.

Para realizar un análisis e interpretación a profundidad de esta situación planteada, es menester analizar el contexto teórico de la situación, desde la óptica objetiva, desde distintas variables, mediante verificación de los hechos, que permitan precisar la real magnitud de los efectos económicos de la migración.

Acosta, en su artículo, La deuda externa de América Latina; origen, evolución y alternativas de solución, deja sentada de manera muy clara su posición, respecto al rol de los países desarrollados con relación a la deuda. Por un lado, se tienen las políticas económicas neoliberales en la década de los 80 y principios del siglo $X X$ de ajuste y reajuste económico que estructuralmente empobrecía a la población debido a que la dirección económica de los gobiernos de turno, estaba orientada al pago de la deuda externa, esto iba en detrimento de la 
atención del estado al fortalecimiento del programa social. (3).

La "eterna lucha" por la reducción de la pobreza y el costo de vida impuesto por el poder adquisitivo de satisfacer necesidades básicas en dólares perjudicó a las familias que dejaron de percibir estas remesas, tomando en cuenta que el ingreso de divisas siempre fue considerado tanto para contrarrestar la salida de dólares, así como un producto del desequilibrio comercial y de servicios.

De esta manera, el efecto de las remesas sobre la pobreza, tuvo su aspecto positivo en relación al consumo de los receptores y su resultado negativo a nivel del poder adquisitivo del ingreso, respecto a la inflación y la distorsionada situación en la que se encontraba la estructura de los precios. En el mismo ámbito, las remesas tuvieron de manera implícita más problemas, el más grave de ellos fue la necesidad de una dependencia externa, que permitía el sustento del consumo interno. Erigióse, entonces, aquel recurso recibido por los núcleos familiares ecuatorianos y enviado por quienes ya no se encontraban en el país, como una piedra angular dentro del contexto presupuestal familiar.

Aunque no debe dejarse de lado que mientras los flujos migratorios tenían escasa posibilidad de lograr un crecimiento de remesas a futuro, la creciente emigración sigue mirando hacia afuera de manera ciega y hasta intentando quedarse en España, Italia, o tal vez en Estados Unidos con todo lo que eso implica, en lugar de regresar, priorizando calidad de vida, más que reunificación familiar. Por ello, es importante destacar que el impulso de las remesas al consumo en su momento fue esencial tanto para la estimulación de áreas de la producción y para el incentivo de la demanda efectiva pretendiendo de este modo una superación de la crisis y la recuperación del Producto Interno Bruto.

En consecuencia, siempre fue preponderante el aporte de las remesas para el crecimiento de todos los sectores, ya sean productivos, comerciales y sociales a nivel local durante todo el Siglo $X X I$, llegando a consolidarse incluso como un "recurso esperado" para lograr ese equilibrio entre el ganar y gastar.

La crisis llegó - y para quedarse - en España: bienes inmuebles sobrevalorados producto de la llamada "burbuja inmobiliaria", cierre de empresas, despido y reducción de personal, contratación de mano de obra más barata (por lo general de ilegales), desempleo, este remezón afectó a los centenares de miles de ecuatorianos radicados en estas tierras, y por ende y a manera de efecto dominó, a los familiares que mes a mes recibían su remesa.

El cambio y la revolución se acentuaron en Ecuador a partir del 2007, transformando de a poco la realidad social del país. La mentalidad de las y los ecuatorianos fue cambiando, pues estos pudieron percibir que en su propio país existía la posibilidad para obtener un trabajo digno que permita el desarrollo económico.

Sin embargo, la brecha ocasionada por la reducción significativa de la migración, ha ocasionado también que el ingreso de remesas disminuya, esto se siente a nivel macro y microeconómico, de manera que era necesario implementar estrategias reflejadas en políticas económicas que buscan precautelar la producción nacional y por ende la salida indiscriminada de divisas, las que al país le cuesta acumular.

Según el informe anual de estadísticas de remesas en la Comunidad Andina Naciones del 2013 los países de origen de las remesas para América latina son, Estados Unidos, España, Venezuela e Italia, a saber: "El año 2012 los principales países de origen de las Remesas para la CAN fueron: Estados Unidos con 3701 millones de dólares americanos, España 2837 millones de dólares americanos, Venezuela con 542 millones de dólares americanos, e Italia con 499 millones de dólares americano" (4).

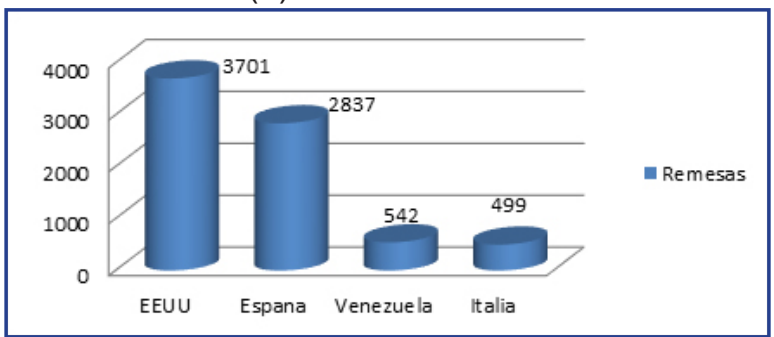

Fuente: Informe Anual de las estadísticas de la CAN 2013 Elaborado por: Autores.

GRÁFICO NO. 1 PAÍSES DE ORIGEN DE REMESAS

Se puede observar que a pesar de la situación económica que atraviesan los países europeos, España se conserva como la segunda fuente más importante de remesas enviadas a América Latina, especialmente al Ecuador, esta referencia es importante para el trabajo elaborado ya que constituye el fundamento del documento.

En Ecuador, el monto de remesas provenientes del exterior en el 2010 es de 2324 millones, en el 2011 el Ecuador recibe 2672, en el 2012 recibe 2446 millones de dólares. Con relación al Producto Interno Bruto en cada uno de los respectivos años, esto significa que para el 2010 fue de 4,4, en el 2011 fue de 3,4 y en el 2012 fue de 2,9 (5).

El objetivo de este trabajo es determinar el nivel 
de afectación en las remesas de los migrantes en el presupuesto familiar en la provincia de Santa Elena.

\section{Desarrollo}

\section{Influencia de las remesas en la Economía de la provincia}

La economía de la provincia de Santa Elena está basada en la agricultura y la pesca, que son actividades artesanales en su gran mayoría, así como también el turismo y la minería, un gran porcentaje de estas actividades son realizadas de una forma autónoma.

No se puede dejar de lado algo que dinamiza también su economía y que son las remesas que envían las personas que han emigrado al exterior, principalmente a España, Italia y EE.UU., de las remesas que reciben los familiares en el Ecuador, de acuerdo con los datos proporcionados por el Instituto Nacional de Estadísticas y Censos (INEC), el $64 \%$ se destinan a la "compra de víveres, ropa u otros"; sólo el $12,1 \%$ se destina a "salud" y el $7 \%$ se consignan al "pago de deudas". El monto de las remesas que se invierten en "educación" corresponden al 9,1\%; así también la inversión en "vivienda o terrenos" alcanza el 4,3\%. El valor de estas transferencias que es destinado al "ahorro" representa solamente el 3,2\%; y las que se invierten en "negocios" escasamente llegan al $0,3 \%(6)$.

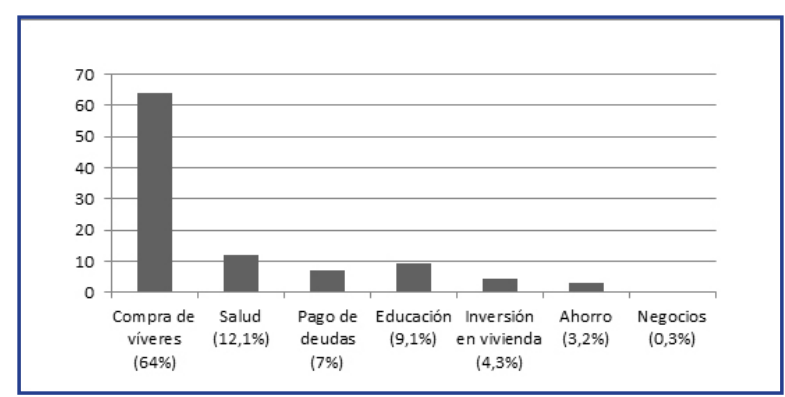

Fuente: Instituto Nacional de Estadísticas y Censo 2010. Elaborado por: Autores

GRÁFICO No. 2. DESTINO DE REMESAS

Según las estadísticas del Banco Central (INEC 2010), España aporta con más del 35\% de las remesas que ingresan al país, por lo que las familias receptoras han sufrido un desbalance en su economía que se evidencia en la disminución del poder adquisitivo y solvencia con la que se gozaba anteriormente, de manera que se han visto afectadas en los proyectos familiares, ya que con el respaldo de las remesas pudieron obtener dinero para educación, salud, créditos para invertir en vivienda, en micro emprendimientos, negocios, en la compra de pequeñas embarcaciones para la pesca y motores para las mismas, entre otras actividades económicas, que fueron un factor determinante para la dinamización de la economía familiar y local.

Según don José Tomalá , padre de 5 hijos, residente en la comuna San Pedro del cantón Santa Elena, las remesas que percibía de su hijo mayor, que se encuentra desde hace 5 años en España, se han ido reduciendo, ya que al principio recibía más de 350 dólares mensuales y en la actualidad recibe un promedio de 250 dólares, lo que le ha dificultado el pago del crédito que obtuvo a través del BNF hace 2 años, para la compra de un motor fuera de borda para su embarcación, que le significaba una mejora en la faena pesquera.

Por otro lado, don Vicente Quimí, de 70 años de edad, quien junto a su esposa quedaron a cargo de sus 3 nietos, hijos de Juan Quimí, hijo mayor de don Vicente, quien envía sus remesas desde España en un monto aproximado de 260 dólares mensuales en relación a los 350 dólares que enviaba hace 3 años atrás, con lo que se han reducido las posibilidades adquisitivas para otros bienes, ya que de este monto pagan 200 dólares mensuales por un crédito que obtuvieron para comprar su vivienda, que la tienen ubicada en el sector La Propicia del cantón la Libertad (Entrevista, 2014).

De acuerdo al Banco de España, el monto actual promedio que se envía de remesas por persona hacia el Ecuador es de 278 dólares mensuales, lo que ha variado, ya que antes de la crisis se enviaban montos entre los 400 a 500 dólares, lo que incide en la economía familiar de las personas que se benefician de dichas remesas; esta variación se debe a que muchas personas han sufrido el paro laboral o desempleo que en este país es de más del $25 \%$, lo que ha afectado a migrantes ecuatorianos y principalmente a los de la provincia de Santa Elena que laboran en ese país o también se debe a la reducción de salarios a los que se han visto forzados para no entrar en este paro laboral (7).

\section{Evolución de las remesas en la Provincia de Santa Elena}

Las personas migrantes de la provincia de Santa Elena a nivel nacional, constituyen el $1 \%$. Las remesas percibidas desde España son aproximadamente el $50 \%$, el resto de remesas se reciben desde Italia, EE.UU. y otros países, en esto radica la importancia que tiene la crisis que atraviesa este país europeo, además hay que tener en cuenta que ésta provincia tiene una característica peculiar, que al ser turística tiene un flujo importante de migración residencial. 
En este sentido lo importante, es que la población migrante de extranjeros que viene a la provincia de Santa Elena influye mucho en cuanto a los envíos, ya que en su mayoría son retirados o jubilados que han fijado su residencia en esta provincia y que reciben sus pensiones, lo que influye en las remesas que percibe nuestro país y obviamente la provincia, además, dentro de los países de origen está: EE.UU., España, Italia, Chile, Argentina, Colombia, Perú, entre otros.

En el año 2010 se benefició con un monto de USD 5.5 millones experimentando una reducción de $2.4 \%$ con relación a 2009 al alcanzar USD 5.6 millones. La Libertad recibió USD 5.1millones, que representa $92.8 \%$ del total de remesas que ingresaron a esta provincia, además, las ciudades de Salinas y Santa Elena lo hicieron en menor proporción (8).

Por concepto de remesas en 2011 se registró USD 9.6 millones, valor que experimentó un aumento de $7.5 \%$ con relación al monto alcanzado en 2010 (USD 8.9 millones). En la Libertad se recibió USD 8.2 millones, que representa el $85.6 \%$ del total de remesas que ingresaron a esta provincia. Igualmente, en las localidades de Santa Elena, Montañita, Salinas y Olón lo hicieron en menor proporción.

En el año 2012 la provincia recibe por remesas USD 12.4 millones, valor que experimentó un aumento de $29.6 \%$ con relación al monto alcanzado en 2011 (USD 9.6 millones). En la Libertad se recibió USD 7.9 millones, que representa el $63.8 \%$ del total de remesas que ingresaron a esta provincia. Igualmente, en las localidades de Santa Elena, Montañita, Salinas y Olón lo hicieron en menor proporción.

De acuerdo con los informes anuales emitidos por el Banco Central del Ecuador, se puede observar cómo han ido evolucionando las remesas en la provincia de Santa Elena en los años 2010, 2011 y 2012.

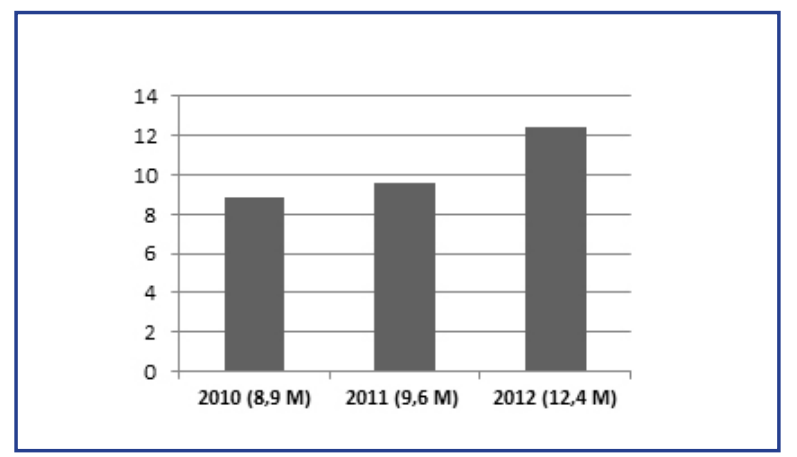

Fuente: Banco Central Del Ecuador 2013.

Elaborado por: Autores.

GRÁFICO No. 3. REMESAS EN MILLONES DE DÓLARES
En cuanto al año 2013 se ha podido obtener estadística de los 3 primeros trimestres del año. Durante el trimestre julio - septiembre de 2013, en la provincia de Santa Elena se recibieron USD 2.4 millones, $7.3 \%$ menor al registrado en el segundo trimestre de 2013 (USD 2.6 millones), e inferior en $54.6 \%$ al observado en el tercer trimestre de 2012 (USD 5.3 millones). El cantón La Libertad aparece como el principal destino de este flujo al recibir USD 1.8 millones, que representó el $73.4 \%$ del monto recibido en esta provincia. El remanente se distribuyó entre las localidades de Santa Elena, Manglaralto y Salinas.

Durante el trimestre abril - junio de 2013, en la provincia de Santa Elena se recibieron USD 2.6 millones, $13.7 \%$ mayor al registrado en el primer trimestre de 2013 (USD 2.3 millones) y superior en $10.8 \%$ al registrado en el segundo trimestre de 2012 (USD 2.4 millones). El cantón La Libertad aparece como el principal destino de este flujo al recibir USD 2.0 millones, que representó el $75.5 \%$ del monto recibido en esta provincia. El remanente se distribuyó entre las localidades de Santa Elena, Manglaralto y Salinas.

Durante el trimestre enero - marzo de 2013, en la provincia de Santa Elena se recibieron USD 2.3 millones, $8.3 \%$ menor al registrado en el cuarto trimestre de 2012 (USD 2.5 millones) y similar al registrado en el primer trimestre de 2012 (USD 2.3 millones). El cantón La Libertad aparece como el principal destino de este flujo al recibir USD 1.9 millones, que representó el $81.7 \%$ del monto recibido en esta provincia (9). El remanente se distribuyó entre las localidades de Manglaralto, Santa Elena y Salinas.

Si bien es cierto que la provincia ha tenido aumentos importantes con respecto a sus remesas, es necesario tener en cuenta que las mismas están globalizadas con las remesas de todos los países que envían, por lo que es necesario analizar los porcentajes en los cuales las remesas enviadas, específicamente, desde España han variado en nuestro país.

Durante 2010, las remesas enviadas por los inmigrantes desde España a Ecuador se redujeron un $4,44 \%$ con respecto al año anterior, según publicó esta semana Remesas.org, sitio especializado en el tema. (10).

En el 2011 el país tiene una recuperación de un $3 \%$ en la recepción de remesas. Para el año 2012 Ecuador sufre una nueva caída en sus remesas, esto es un 8,3\% menos con respecto al 2011, algo que el reporte atribuye debilidad de la economía española, donde se encuentra la principal 
población emigrante del país andino.

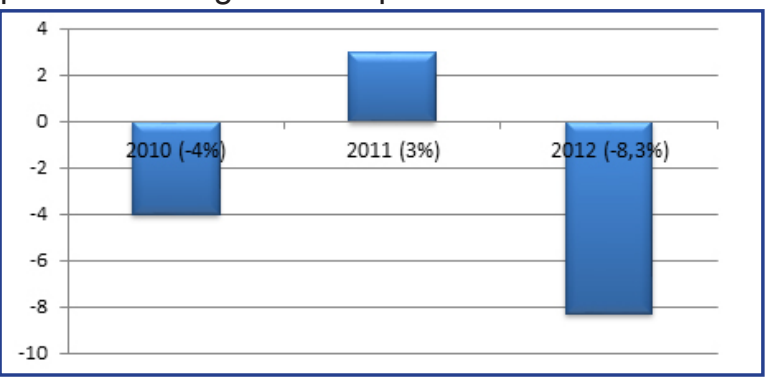

Fuente: Banco Central Del Ecuador 2013.

Elaborado por: Autores.

GRÁFICO NO. 4. REMESAS EN \%

Estos porcentajes demuestran que las familias que reciben las remesas desde España han sufrido un déficit en cuanto a los montos que perciben por este concepto, y en los hogares de la provincia de Santa Elena esto no es una excepción, ya que las personas que tienen sus parientes en España se quejan de la caída en cuanto a los montos que reciben desde este país.

En cuanto a los aumentos generales de remesas en la provincia, se debe a que los migrantes residentes permanentes reciben pensiones jubilares mayores a 1.500 dólares mensuales, y que el número de estas familias se ha ido incrementando anualmente en la provincia. Además, cabe recalcar que a pesar de la crisis que soportan los países receptores de los migrantes, los ecuatorianos y en especial los habitantes de Santa Elena no han dejado de migrar hacia estos destinos, de acuerdo a datos obtenidos en las oficinas de Migración de Guayaquil, lo que permite acrecentar la llegada de remesas a esta provincia.

\section{Conclusión}

La migración fue un hecho trascendental dentro de la historia ecuatoriana de fines del siglo XX, $y$ esos migrantes incidieron positivamente en el despertar económico nacional.

La provincia de Santa Elena, dentro del contexto del envío de remesas es un caso especial, ya que se ha observado un aumento considerable de las mismas, a diferencia del promedio nacional.

Este hecho se da por la llegada de jubilados extranjeros radicados en la provincia, especialmente en Salinas, quienes reciben mes a mes dinero proveniente de su jubilación o de sus familiares.

\section{Referencias Bibliográficas}

1. INEC. Ecuadorencifras. Retrieved from ecuadorencifras.gob.ec/: (2010, Noviembre 25). http:// www.ecuadorencifras.gob.ec/
2. Alberto Acosta, S. L. (n.d.). Las remesas y su impacto macroeconómico. In L. r. macroeconómico, Las remesas y su aporte para la economía ecuatoriana s/d, s/f.

3. Acosta Alberto, La deuda externa de América Latina: origen, evolución y alternativas de solución. Políticas utilizadas por el FMI, y BM. http:// www.oid-ido.org/IMG/pdf/ACOSTA01.pdf

4. CAN. Comunidad Andina. Retrieved from Comunidad Andina: (2013, Agosto 2). http//intranet. comunidadandina.org/Documentos/DEstadisticos/SGde425.pdf

5. CAN.. Comunidad Andina . Retrieved from Comunidad Andina: (2013) http://estadisticas.comunidadandina.org/eportal/contenidos/2346_8.pdf

6. INEC. Censo Nacional Económico 2010 - Unidad de Procesamiento de la Subdirección General del INEC, SENPLADES - Subsecretaría de Información.gob.ec/: (2010) http://www.ecuadorencifras.gob.ec/

7. Banco Central del Ecuador Boleaq tines estadísticos mensuales. "Las remesas de los emigrantes ecuatorianos". Cuaderno de Trabajo, $\mathrm{N}^{\circ}$ 130. Quito, Dirección General de Estudios. (2010 - 2012).

8. BID-FOMIN. Las remesas de emigrantes entre España y Latinoaméri - ca. Washington D.C., BID. (2012).

9. Banco Central del Ecuador estadísticos "Las remesas de los emigrantes ecuatorianos". Quito, Dirección General de Estudios. (2013).

10. Investigación para el Fondo Multilateral de Inversiones -FOMIN- del Banco Interamericano de Desarrollo -BID-, Pew Hispanic Center -PHC-.

\section{Notas}

${ }^{1}$ Acosta Alberto, La deuda externa de América Latina: origen, evolución y alternativas de solución. Ecuatoriano. Economista, Universidad de Colonia, Alemania. Consultor internacional y del Instituto Latinoamericano de Investigaciones Sociales, ILDIS-FES (Ecuador). Profesor visitante de las Universidad; de Cuenca, Guayaquil. Asesor de organizaciones indígenas y sociales. Editorialista del Diario Hoy, Quito. Ex presidente de la asamblea Nacional Constituyente del Ecuador.

2 Entrevista realizada al señor Tomalá José y Vicente Quimí, respecto a la utilización del dinero que el recibe de sus familiares en España. 